\title{
Governmental and Private Dentists' Knowledge, Educational Background, Opinion, and Clinical Experience toward Obstructive Sleep Apnea and Oral Appliances
}

\author{
${ }^{1}$ Saeed M Banabilh, ${ }^{2}$ Rasha Al-afaleg
}

\section{ABSTRACT}

Aim: The aims of this study were to determine the knowledge, educational background, opinion, and clinical experience of general practice dentists toward obstructive sleep apnea (OSA) and oral appliances (OAs).

Materials and methods: A cross-sectional study was carried out through a questionnaire which was distributed randomly to 200 general practice dentists both in public and private dental clinics at Qassim, Kingdom of Saudi Arabia. About 175 completed questionnaires were returned. The data were statistically analyzed using Statistical Package for the Social Sciences (SPSS).

Results: The results showed that only $48.6 \%$ of our governmental and private dentists were familiar with the term OSA with a statistical significance among governmental dentists (37.9\%) who were more familiar with OSA signs and symptoms than private $(21.1 \%)$ dentists $(p<0.016)$. In addition, the majority of the respondents $(90.9 \%)$ reported a general lack of education in both OSA and OAs during their study in the dental school. A total of $142(81.1 \%)$ dentists never prescribed OAs for OSA patients. However, $87.4 \%$ have never consulted or referred a suspected OSA patient to physicians.

Conclusion: General practice dentists surveyed possess poor knowledge and low clinical experience regarding OSA and OAs, which reflects the weak level of education in this field of dental sleep medicine.

Keywords: Awareness, Clinical experience, Education, Knowledge, Obstructive sleep apnea, Opinion, Oral appliance.

How to cite this article: Banabilh SM, Al-afaleg R. Governmental and Private Dentists' Knowledge, Educational Background, Opinion, and Clinical Experience toward Obstructive Sleep Apnea and Oral Appliances. J Contemp Dent 2017;7(3): 139-143.

Source of support: Nil

Conflict of interest: None

${ }^{1}$ Assistant Professor, ${ }^{2}$ Teaching Assistant

1,2Department of Orthodontics and Pedodontics, College of Dentistry, Qassim University, Buraidah, Qassim, Kingdom of Saudi Arabia

Corresponding Author: Saeed M Banabilh, Assistant Professor, Department of Orthodontics and Pedodontics, College of Dentistry, Qassim University, Buraidah, Qassim, Kingdom of Saudi Arabia, e-mail: banabilh23@gmail.com

\section{INTRODUCTION}

Obstructive sleep apnea is a big public health problem characterized by recurrent events of upper airway obstruction during sleep associated with clinical signs and symptoms. ${ }^{1,2}$ Obstruction may involve awakening under the effect of increased respiratory effort and a reduction (hypopnea) or complete cessation (apnea) of airflow in the presence of respiratory movements. ${ }^{3}$ Recent epidemiological research showed a high prevalence of undiagnosed OSA in terms of morbidity and significant associations between OSA and serious medical and social problems, such as hypertension, cardiovascular disease, stroke, and automobile crashes, with overall negative effects on the quality of life. ${ }^{4}$

A National Center on Sleep Disorders study estimated that between 50 and 70 million Americans are affected by a sleep disorder. ${ }^{5}$ In the Middle East, 3 out of 10 Saudi men and 4 out of 10 Saudi women are at a high risk of developing OSA. ${ }^{6,7}$ In the United Arab Emeritus (UAE), the prevalence of symptoms of OSA among adult UAE citizens was found to be very high, and highest prevalence observed was between ages 51 and 60 years in both genders. ${ }^{8}$ It is clear that OSA is a medical problem and primary care physicians play important role in the detection and proper referral of patients with OSA. Dentists can also play a big role in recognizing OSA, involving in OSA diagnosis, making appropriate recommendations and referrals for OSA patients, and treating OSA with OAs. ${ }^{910}$ Moreover, dentists could be the first healthcare providers to notice the signs and symptoms of the disease, such as a long soft palate, macroglossia, or a small mandible. ${ }^{11}$ Nevertheless, awareness regarding sleep disorders is insufficient among dentists. Thus, a significant number of patients with sleep disorders remain undiagnosed as a result of limited dental sleep medicine education among healthcare providers. ${ }^{2,10}$ Most previous studies focused primarily on physicians' knowledge and attitudes toward sleep disorders. ${ }^{12}$ Some investigations evaluated the nature and extent of sleep medicine provided in medical schools, ${ }^{13-15}$ but there were fewer studies that focused on the role of the dentists and their knowledge in relation to sleep disorders and their treatment modalities 
especially in Kingdom of Saudi Arabia. Therefore, the aims of this study were to determine knowledge, educational background, opinion, and clinical experience of general practice dentists toward OSA and OAs.

\section{MATERIALS AND METHODS}

A cross-sectional study through a questionnaire-based survey was conducted among a sample of general practicing dentists both in public and private dental clinics at Qassim Province, Kingdom of Saudi Arabia. Ethical approval and informed consent for carrying out the present study was obtained from the ethical committee at Dental Research Centre (DRC), College of Dentistry, Qassim University. A list of dentists and specialist in Qassim was then obtained from the list of Saudi Commission for Health Specialties database. A random number generator was then used to select 200 dentists from this database. Those dentists who were unable or unwilling to fill the complete questionnaire were excluded. The purpose of the study was explained to each participant, and consent form were obtained prior to the distribution of the study questionnaire. The questionnaires were distributed and collected back again after being completed. The paper-based questionnaire used in the study was an anonymous self-administered pretested structured questionnaire that was developed and validated by Bian. ${ }^{9}$ The questionnaire consisted of 21 questions: The first 5 questions comprised items on demographic data: Age, gender, education level, whether they worked in public or private clinics, and years of experience. Some of the questions were designed to assist knowledge and clinical experience of the participants about OSA and OAs, such as "OSA is a potential life-threatening illness"; "For some OSA patients, an oral appliance is an effective treatment"; "Dentists and physicians should cooperate in dealing with OSA"; "Obstructive sleep apnea is a medical problem, but dentists can detect, diagnose, and treat it." Respondents were asked to use a 4-point Likert-type scale (strongly agree to strongly disagree) to answer the opinion on items. Other items asked participants to recall their previous clinical experiences regarding OSA and OAs using the following questions: "How many times have you consulted with physicians for a suspected OSA patient in your practice?", "How many times have you been referred OSA patients by physicians?," and "How many times have you prescribed OAs for OSA patients?" The last three questions evaluated participants' previous knowledge of OSA and OAs, such as "Did you learn about OSA in your dental school?," "Did you attend any postgraduate course about OSA?," and "Would you like to attend OSA course?" Each question offered two response choices: yes or no. Collected data were analyzed using the SPSS, version 19. The questions were given variable names from Q1 to Q21 of the questionnaire. Then the choices in each question got a numeric value relevant to the corresponding answer of each participant.

Descriptive statistics were performed using frequency count and percentages. The $\chi^{2}$ test was performed to determine the difference between the studied groups at the $5 \%$ level of significance.

\section{RESULTS}

Out of 200 questionnaires distributed, 175 were returned; the response rate was $87.5 \%$. Table 1 shows the sociodemographic and background characteristics of the study sample.

\section{Knowledge}

Only $48.6 \%$ of our governmental and private dentists were familiar with the term OSA. A statistical significance was found among governmental dentists (37.9\%) who were more familiar with OSA signs and symptoms than private $(21.1 \%)$ dentists $(\mathrm{p}<0.016)$. Both governmental and private dentists agree that OSA is a potential life-threatening illness (92.6\%); dentists and physicians should deal with OSA $(94.3 \%)$, and OSA is a medical problem that can be detected, diagnosed, and treated by dentists with no statistically significant difference regarding their agreement (Table 2).

\section{Educational Background}

Majority of our dentists (90.9\%) did not learn about OSA and OA when they were in dental schools. Similarly, the majority of governmental dentists $(81.8 \%)$ and private dentists $(79.8 \%)$ did not attend any course on management of OSA. However, most of them (95.4\%) were interested in attending OSA management courses (Table 3).

Table 1: Distribution of studied cases according to demographic data

\begin{tabular}{ll}
\hline Variables & $n=175(\%)$ \\
\hline Gender & $104(59.4)$ \\
Male & $71(40.6)$ \\
Female & \\
Place of work & $66(37.7)$ \\
Governmental & $109(62.3)$ \\
Private & \\
College of graduation & $136(77.7)$ \\
Governmental & $39(22.3)$ \\
Private & \\
Specialty & $142(81.1)$ \\
General practitioner & $33(18.9)$ \\
Specialist &
\end{tabular}


Table 2: Dentists' knowledge toward sleep apnea

\begin{tabular}{|c|c|c|c|c|c|}
\hline & & & lace of work & & \\
\hline & & Governmental & Private & Total & \\
\hline & & No (\%) & No $(\%)$ & No (\%) & $\chi^{2}(p)$ \\
\hline Familiar with the term OSA & Yes & $37(56.1)$ & $48(44.0)$ & $85(48.6)$ & 0.123 \\
\hline & No & $29(43.9)$ & $61(56.0)$ & $90(51.4)$ & \\
\hline Know the common signs and symptoms of OSA & Yes & $25(37.9)$ & $23(21.1)$ & $48(27.4)$ & $0.016^{*}$ \\
\hline & No & $41(62.1)$ & $86(78.9)$ & $127(72.6)$ & \\
\hline Agree that OSA is a potential life-threatening illness & Agree & $58(87.9)$ & $104(95.4)$ & $162(92.6)$ & 0.065 \\
\hline & Disagree & $8(12.1)$ & $5(4.6)$ & $13(7.4)$ & \\
\hline Agree that dentists and physicians should deal with OSA & Agree & $62(93.9)$ & $103(94.5)$ & $165(94.3)$ & 0.878 \\
\hline & Disagree & $4(6.1)$ & $6(5.5)$ & $10(5.7)$ & \\
\hline Agree that OSA is a medical problem, but dentists can & Agree & $52(78.8)$ & $85(78.0)$ & $137(78.3)$ & 0.9 \\
\hline detect, diagnose, and treat it & Disagree & $14(21.2)$ & $24(22.0)$ & $38(21.7)$ & \\
\hline
\end{tabular}

Table 3: Dentists' educational background toward sleep apnea

\begin{tabular}{|c|c|c|c|c|c|}
\hline & & \multicolumn{3}{|c|}{ Place of work } & \multirow[b]{3}{*}{$\chi^{2}(p)$} \\
\hline & & Governmental & Private & Total & \\
\hline & & No (\%) & No $(\%)$ & No (\%) & \\
\hline \multirow[t]{2}{*}{ Did you learn about OSA and OA when you were in dental school? } & Yes & $5(7.6)$ & $11(10.1)$ & $16(9.1)$ & \multirow[t]{2}{*}{0.576} \\
\hline & No & $61(92.4)$ & $98(89.9)$ & $159(90.9)$ & \\
\hline \multirow{2}{*}{$\begin{array}{l}\text { Did you attend any courses on the management of sleep apnea or } \\
\text { socially disruptive snoring? }\end{array}$} & Yes & $12(18.2)$ & $22(20.20)$ & $34(19.4)$ & \multirow[t]{2}{*}{0.746} \\
\hline & No & $54(81.8)$ & $87(79.8)$ & $141(80.6)$ & \\
\hline \multirow{2}{*}{$\begin{array}{l}\text { Are you interested in attending a course on the dentist's role in the } \\
\text { management of sleep disorders? }\end{array}$} & Yes & $62(93.9)$ & $105(96.3)$ & $167(95.4)$ & \multirow[t]{2}{*}{0.463} \\
\hline & No & $4(6.1)$ & $4(3.7)$ & $8(4.6)$ & \\
\hline
\end{tabular}

Table 4: Dentists' opinion toward sleep apnea

\begin{tabular}{|c|c|c|c|c|c|}
\hline & & \multicolumn{3}{|c|}{ Place of work } & \multirow[b]{3}{*}{$\chi^{2}(p)$} \\
\hline & & Governmental & Private & Total & \\
\hline & & No (\%) & No (\%) & No (\%) & \\
\hline \multirow{2}{*}{$\begin{array}{l}\text { Do you think that for some OSA patients OAs are an } \\
\text { effective treatment? }\end{array}$} & Agree & $35(53.0)$ & $77(70.6)$ & $112(64.0)$ & \multirow[t]{2}{*}{$0.019^{*}$} \\
\hline & Disagree & $31(47.0)$ & $32(29.4)$ & $63(36.0)$ & \\
\hline \multirow{2}{*}{$\begin{array}{l}\text { Would you discuss any side-effects of OAs with your } \\
\text { patient? }\end{array}$} & Yes & $26(39.4)$ & 65 (59.6) & $91(52.0)$ & \multirow[t]{2}{*}{$0.009^{*}$} \\
\hline & No & $40(60.6)$ & $44(40.4)$ & $84(48.0)$ & \\
\hline
\end{tabular}

*Significant at $p<0.05$

\section{Opinion}

Opinions about OSA showed statistically significant differences between both groups. About $70.6 \%$ of private dentists think that for some OSA patients, OAs are an effective treatment, while $53 \%$ of governmental dentists believe in that $(\mathrm{p}<0.019)$. Most private dentists $(59.6 \%)$ discuss the side effects of OA with their patients.

On the contrary, the majority of governmental dentists did not discuss that with their patients $(\mathrm{p}<0.009$; Table 4$)$.

\section{Clinical Experience}

Clinical experience variable showed that $76.6 \%$ of dentists had infrequently seen patients with chronic snoring or possible OSA. Majority of dentists either governmental or private do nothing for their patients with chronic snoring or OSA. Most dentists did not consult physicians for their cases. Prescriptions of OAs were only done by $22.7 \%$ of governmental dentists and $19.3 \%$ of the private dentist, and a small number of governmental and private dentists (9.1 and $11.9 \%$ respectively) treated their patients with these OAs (Table 5).

\section{DISCUSSION}

Several studies have assessed medical students' knowledge in the field of sleep medicine. ${ }^{14,15}$ The literature is lacking significant research to assess sleep medicine knowledge and education among dental students or general practice dentists. General practice dentists are more likely to be among the first to contact who detect, refer, or treat potential OSA patients. ${ }^{16}$ Therefore, this current study was carried out to investigate the knowledge, educational background, opinion, and clinical experiences of general practice dentists in both government and private clinic 
Table 5: Dentists' clinical experience toward sleep apnea

\begin{tabular}{|c|c|c|c|c|c|}
\hline & & \multicolumn{3}{|c|}{ Place of work } & \multirow[b]{3}{*}{$\chi^{2}(p)$} \\
\hline & & Governmental & Private & Total & \\
\hline & & No (\%) & No (\%) & No (\%) & \\
\hline \multirow[t]{4}{*}{ See patients with chronic snoring or possible OSA } & Frequently & $10(15.2)$ & $16(14.7)$ & $26(14.9)$ & \multirow[t]{4}{*}{0.182} \\
\hline & Infrequently & $51(77.3)$ & $83(76.1)$ & $134(76.6)$ & \\
\hline & Occasionally & $4(6.1)$ & $2(1.8)$ & $6(3.4)$ & \\
\hline & Never & $1(1.5)$ & $8(7.3)$ & $9(5.1)$ & \\
\hline \multirow{4}{*}{$\begin{array}{l}\text { Treatment of patients with possible OSA or } \\
\text { chronic snoring }\end{array}$} & Nothing & $30(45.5)$ & $44(40.4)$ & $74(42.3)$ & \multirow[t]{4}{*}{0.813} \\
\hline & Lifestyle advice & $12(18.2)$ & $21(19.3)$ & $33(18.9)$ & \\
\hline & $\mathrm{OA}$ & $12(18.2)$ & $26(23.9)$ & $38(21.7)$ & \\
\hline & Referred to sleep clinic & $12(18.2)$ & $18(16.5)$ & $30(17.1)$ & \\
\hline \multirow{2}{*}{$\begin{array}{l}\text { Consult with physicians for a suspected OSA } \\
\text { patient in your practice }\end{array}$} & Yes & $12(18.2)$ & $14(12.8)$ & $26(14.9)$ & \multirow[t]{2}{*}{0.336} \\
\hline & No & $54(81.8)$ & $95(87.2)$ & $149(85.1)$ & \\
\hline \multirow[t]{2}{*}{ Patients being referred as OSA by physicians } & Yes & $12(18.2)$ & $14(12.8)$ & $26(14.9)$ & \multirow[t]{2}{*}{0.336} \\
\hline & No & $54(81.8)$ & $95(87.2)$ & $149(85.1)$ & \\
\hline \multirow[t]{2}{*}{ Prescribed OAs for OSA patients } & Yes & $15(22.7)$ & $21(19.3)$ & $36(20.6)$ & \multirow[t]{2}{*}{0.583} \\
\hline & No & $51(77.3)$ & $88(80.7)$ & $139(79.4)$ & \\
\hline \multirow[t]{2}{*}{ Provide patients with OAs } & Yes & $6(9.1)$ & $13(11.9)$ & $19(10.9)$ & \multirow[t]{2}{*}{0.559} \\
\hline & No & $60(90.9)$ & $96(88.1)$ & $156(89.1)$ & \\
\hline
\end{tabular}

toward OSA and OAs. The result showed that $48.6 \%$ of our governmental and private practicing dentists were familiar with the term OSA, and $59.0 \%$ of our governmental (37.9\%) and private (21.1\%) dentists were familiar with OSA signs and symptoms. This result also showed that governmental practicing dentists were more familiar with OSA signs and symptoms than private practicing dentists $(\mathrm{p}<0.016)$. This could be attributable to the nature of government dentists' place of work where they are surrounded by many medical specialties. Previous studies also reported similar data for different countries. For example, $75 \%$ of US dentists could recognize the definition of OSA but $58 \%$ of them did not know possible common signs and symptoms of OSA. ${ }^{9}$ The lack of knowledge regarding sleep medicine among our general practice dentists in both government and private sector is the result of the limited time assigned for teaching sleep medicine in dental schools, as only 16 (9.1\%) out of 175 dentists learned about OSA and OAs in dental school; $159(90.9 \%)$ knew little or nothing about this issue.

Results of this study are consistent with other findings, which showed that dental school education and postgraduate training seem to fall off behind clinical developments in sleep medicine and sleep dentistry. For example, a survey of medical schools in the United States reported that fewer than 2 hours of the medical education curriculum was devoted to sleep and sleep disorders. ${ }^{17-19}$ A more recent survey on sleep education in the Medical School curriculum in 12 countries in the Asia-Pacific region and North America reported that the overall time allocated to sleep education was less than 2.5 hours. ${ }^{15}$ The mean number of hours devoted to sleep medicine in the majority of US dental hygiene program curricula was 1.5 hours..$^{20}$ Similarly, this phenomenon is seen more clearly in the Middle East dental schools, as only nine Middle East dental schools (23\%) reported the inclusion of sleep medicine in their undergraduate curriculum compared with $75.5 \%$ of the US dental schools, with a total average hours dedicated to teaching sleep medicine in the corresponding dental schools was 1.2 hours. ${ }^{15}$ This level of education at many dental schools is inadequate to prepare dentists for their potential role in patient education, screening, and management of sleeprelated breathing disorders as the early detection and management of patients with sleep disorders depends considerably on the knowledge and awareness of practicing dentist. In addition, $85.1 \%$ of our sample reported that they do not refer OSA patients to physicians, which indicates either poor communication in our medical and dental professional communities or the lack of knowledge among physicians about OAs as a more suitable or alternative treatment than medical therapy for some patients. The lack of knowledge among general practicing dentists in our sample helps explain the inability to detect OSA patients in their clinics. In consequence, $20.6 \%$ prescribed OA for OSA patients and $10.9 \%$ provide patients with OAs. A considerable number of studies have proved the effectiveness of OAs. ${ }^{21-23}$ Unfortunately, because sleep medicine education in our sample dental schools is highly limited, it is likely that sleep disorders will be underrecognized and that patients with these disorders may be inaccurately diagnosed and may receive inappropriate treatment. It has been demonstrated that doctors who receive training in sleep disorders are more likely to recognize and treat sleep disorders ${ }^{14}$ In practice, dentists should consider more attention to two important 
matters. First, before dentists assume responsibility for an OSA patient, they should prepare themselves with information about sleep medicine and OAs. ${ }^{21}$ Second, team approach best manages OSA. Cooperation between dentists and physicians provide professional communication and mutual respect, which is critical for managing the health and well-being of patients. ${ }^{24,25}$

As a result of this research, we highly recommend two measures: First, an introduction and increase of the number of hours of teaching dedicated to sleep medicine in different courses in the curriculum related to sleep disorders; and second, an urgent need for increasing the awareness and training regarding OSA and OAs in dental school.

\section{CONCLUSION}

General practice dentists surveyed possess poor knowledge and low clinical experience regarding OSA and OAs, which reflects the weak level of education in this field of dental sleep medicine.

\section{CLINICAL SIGNIFICANCE}

These results suggest the urgent need for increasing the education background, awareness, and training regarding OSA and OAs in dental school, as well as improvement in the cooperation between dentists and physicians for better patient care.

\section{REFERENCES}

1. Phillipson EA. Sleep apnea-a major public health problem. N Engl J Med 1993 Apr;328(17):1271-1273.

2. Young T, Palta M, Dempsey J, Skatrud J, Weber S, Badr S. The occurrence of sleep-disordered breathing among middleaged adults. N Engl J Med 1993 Apr;328(17):1230-1235.

3. Epstein LJ, Kristo D, Strollo PJ Jr, Friedman N, Malhotra A, Patil SP, Ramar K, Rogers R, Schwab RJ, Weaver EM, et al. Clinical guideline for the evaluation, management and longterm care of obstructive sleep apnea in adults. J Clin Sleep Med 2009 Jun;5(3):263-276.

4. Lurie A. Obstructive sleep apnea in adults: epidemiology, clinical presentation, and treatment options. Adv Cardiol 2011 Oct;46:1-42.

5. National Sleep Disorders Research Plan. Sleep 2003 May; 26(3):253-257.

6. BaHammam AS, Alrajeh MS, Al-Jahdali HH, BinSaeed AA. Prevalence of symptoms and risk of sleep apnea in middleaged Saudi males in primary care. Saudi Med J 2008 Mar; 29(3):423-426.

7. Bahammam AS, Al-Rajeh MS, Al-Ibrahim FS, Arafah MA, Sharif MM. Prevalence of symptoms and risk of sleep apnea in middle-aged Saudi women in primary care. Saudi Med J 2009 Dec;30(12):1572-1576.
8. Mahboub B, Afzal S, Alhariri H, Alzaabi A, Vats M, Soans A. Prevalence of symptoms and risk of sleep apnea in Dubai, UAE. Int J Gen Med 2013 Mar;6:109-114.

9. Bian H. Knowledge, opinions, and clinical experience of general practice dentists toward obstructive sleep apnea and oral appliances. Sleep Breath 2004 Jun;8(2):85-90.

10. Bailey DR. Snoring and sleep apnea: the dentist's role in treatment. Dent Today 2000 Nov;19(11):52-55.

11. Haviv Y, Benoliel R, Bachar G, Michaeli E. On the edge between medicine and dentistry: review of the dentist's role in the diagnosis and treatment of snoring and sleep apnea. Quintessence Int 2014 Apr;45(4):345-353.

12. Phillips B, Collop N, Goldberg R. Sleep medicine practices, training, and attitudes: a wake-up call for pulmonologists. Chest 2000 Jun;117(6):1603-1607.

13. McIntosh AE, MacMillan M. The knowledge and educational experiences of student nurses regarding sleep promotion in hospitals. Nurse Educ Today 2009 Oct;29(7):796-800.

14. Almohaya A, Qrmli A, Almagal N, Alamri K, Bahammam S, Al-Enizi M, Alanazi A, Almeneessier AS, Sharif MM, Bahammam AS. Sleep medicine education and knowledge among medical students in selected Saudi Medical Schools. BMC Med Educ 2013 Sep;13:133.

15. Talaat W, AlRozzi B, Kawas SA. Sleep medicine education and knowledge among undergraduate dental students in Middle East universities. Cranio 2016 May;34(3):163-168.

16. Barsh LI. Dentistry's role in the recognition and treatment of sleep-breathing disorders: the need for cooperation with the medical community. J Calif Dent Assoc 1998 Aug;26(8):591-598.

17. Rosen RC, Rosekind M, Rosevear C, Cole WE, Dement WC. Physician education in sleep and sleep disorders: a national survey of U.S. medical schools. Sleep 1993 Apr;16(3):249-254.

18. Rosen R, Mahowald M, Chesson A, Doghramji K, Goldberg R, Moline M, Millman R, Zammit G, Mark B, Dement W. The Taskforce 2000 survey on medical education in sleep and sleep disorders. Sleep 1998 May;21(3):235-238.

19. Rogers RR. Dental sleep medicine: coming of age. Gen Dent 2001 Jul-Aug;49(4):398-400.

20. Minichbauer BC, Sheats RD, Wilder RS, Phillips CL, Essick GK. Sleep medicine content in dental hygiene education. J Dent Educ 2015 May;79(5):484-492.

21. Marchese-Ragona R, Manfredini D, Mion M, Vianello A, Staffieri A, Guarda-Nardini L. Oral appliances for the treatment of obstructive sleep apnea in patients with low C-PAP compliance: a long-term case series. Cranio 2014 Oct;32(4):254-259.

22. Gotsopoulos H, Chen C, Qian J, Cistulli PA. Oral appliance therapy improves symptoms in obstructive sleep apnea: a randomized, controlled trial. Am J Respir Crit Care Med 2002 Sep;166(5):743-748.

23. Rose EC, Barthlen GM, Staats R, Jonas IE. Therapeutic efficacy of an oral appliance in the treatment of obstructive sleep apnea: a 2-year follow-up. Am J Orthod Dentofacial Orthop 2002 Mar;121(3):273-279.

24. Veis RW. Snoring and obstructive sleep apnea from a dental perspective. J Calif Dent Assoc 1998 Aug;26(8):557-565.

25. L'Estrange PR, Battagel JM, Nolan PJ, Harkness B, Jorgensen GI. The importance of a multidisciplinary approach to the assessment of patients with obstructive sleep apnoea. J Oral Rehabil 1996 Jan;23(1):72-77. 